\title{
Design of Special Plastic Bearings and Their Application in Renewable Energy Conversion System
}

\author{
Yongjun Dong ${ }^{1,2}$, Wanqiang Zhu ${ }^{1,2}$, Xueming Zhang ${ }^{1,2}$ and Jingfu Guo ${ }^{*}, 1,2$ \\ ${ }^{I}$ School of Physics, Northeast Normal University, 5268 Renmin Street, Changchun, Jilin Province, China \\ ${ }^{2}$ Key Laboratory of Advanced Energy Development and Application Innovation under Jilin province, 5268 Renmin \\ Street, Changchun, Jilin Province, China
}

\begin{abstract}
To improve the operational reliability of renewable energy conversion system, high-performance polymers and engineering plastics are used to make some parts and components of the energy conversion device, especially in the marine renewable energy generation field. In this article, special plastic bearings based on the material of polyoxymethylene (POM) were designed and applied in the power generation device of both tidal current energy and island wind energy. The properties of POM were analyzed, and the load of a POM ball was tested. Special structures of the plastic bearings were designed to meet the requirements of pressure resistance and to reduce the friction. These plastic bearings had been used in the prototypes of $20 \mathrm{~kW}$ tidal current turbine generation device and $15 \mathrm{~kW}$ island wind turbine generation device. According to the prototypes' operation, the results indicate that these plastic bearings work well and are very suitable for the application in renewable energy conversion system. By optimizing the structure, such plastic bearings would be generalized and applied in the renewable energy generation device with a higher power level.
\end{abstract}

Keywords: High-performance polymers, High pressure resistance, Low friction, POM, renewable energy conversion system.

\section{INTRODUCTION}

Engineering plastics are a group of plastic materials that possess excellent comprehensive properties [1-3], such as strong rigidity, high specific strength, less creep, good corrosion resistance, high thermal stability, electrical insulation, ease of manufacturing, and so on. They have been widely applied in machinery, automotive, appliance, architecture, chemical industry and other fields [4, 5]. However, owing to relatively expensive price, most engineering plastics are often fabricated as some smaller components. Now, they are moving towards higher performance, higher function, multi-purpose and lower cost. With the cost reducing unceasingly, high-grade engineering plastics have gradually replaced metals in many applications. As one of the five important engineering plastics [6-8], polyoxymethylene (POM) is relatively close to the metal in the respects of specific strength and stiffness among all kinds of plastics. Therefore, POM has been used widely in modern industry field, such as the manufacture of all kinds of sliding and rotating mechanical parts.

With the shortage of fossil energy and global climate change caused by $\mathrm{CO}_{2}$ emission, people have focused on the development and utilization of renewable energy. Power generation is one of the main ways of renewable energy utilization. In renewable energy generation system, bearing is one of the key components, especially in the devices of both tidal current turbine and island wind turbine. Because of

*Address correspondence to this author at the School of Physics, Northeast Normal University, 5268 Renmin Street, Changchun, Jilin Province, China; Tel: +86 431 85099278; Fax: +86 431 85099278;

E-mail: renewableerlab@163.com specific marine environments, the most important problems of traditional metal bearings are corrosion and lubrication. The application of high-performance engineering plastics could solve these problems.

In this article, the properties of POM composites including self-lubrication, friction wear, corrosion resistance and mechanical strength were analyzed. Both the static load of one size of POM ball and the impact strength of one POM piece were tested. According to the structure and operation characteristics of tidal current turbine and island wind turbine, specific plastic bearings were designed and applied in the generation system prototypes of both $20 \mathrm{~kW}$ tidal current turbine and $15 \mathrm{~kW}$ island wind turbine. The prototypes' operation based on such plastic bearings was given and discussed.

\section{SPECIFIC BEARING SYSTEM}

\subsection{Background}

To solve the power supply in island, our group carried out the research of standalone island wind turbine generation system with high reliability funded by State Oceanic Administration of China. Meanwhile, to develop the tidal current energy, our group conducted the research of $20 \mathrm{~kW}$ marine tidal current turbine generation system funded by Ministry of Science and Technology of China. The generation system prototypes of island wind energy and tidal current energy that still operate until now are respectively illustrated in Fig. (1a, b). One of the key components in these generation device is bearing. Because of the particularity of the marine environment, two important problems to be resolved in the bearing system are corrosion 


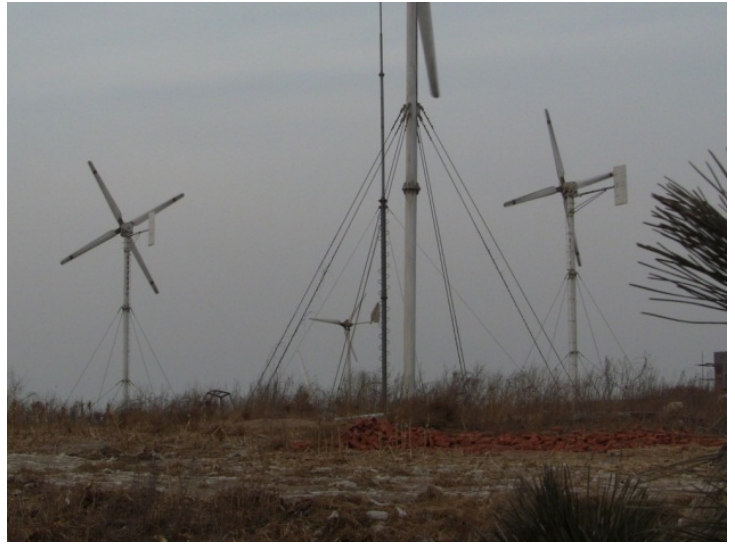

(a)

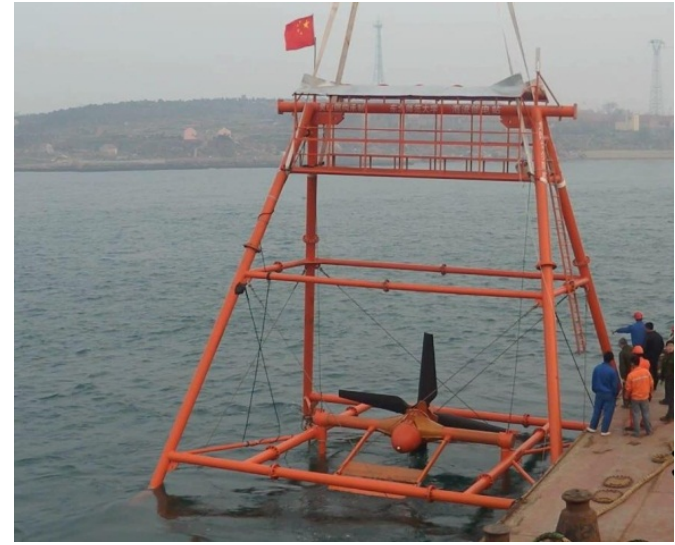

(b)

Fig. (1). Prototypes of renewable energy generation system that adopted the special bearings in Qingdao, Shandong Province: (a) $15 \mathrm{~kW}$ standalone island wind turbine generation device (the two four-blade wind turbines) in Daguan Island; (b) 20kW tidal current turbine generation device near Zhaitang Island.

and lubrication. In this condition, specific bearings should be designed based on modern engineering materials and the structures of the generation system.

\subsection{Bearing Features}

Both of the two generation systems illustrated in Fig. (1) include various bearing devices. In the small-scale wind turbine generation system, we mainly developed the yaw wheel bearing, including the axial part and the radial part, which are shown in Fig. (2). The axial part mainly supports the friction during the yaw of the turbine and the pressure produced by the blades, the hub, the generator and the tail vane. For this part, the bearing should have less friction coefficient and higher compressive strength. The radial part mostly bears the thrust generated by the wind flowing through the turbine and the friction during the yaw of the turbine.

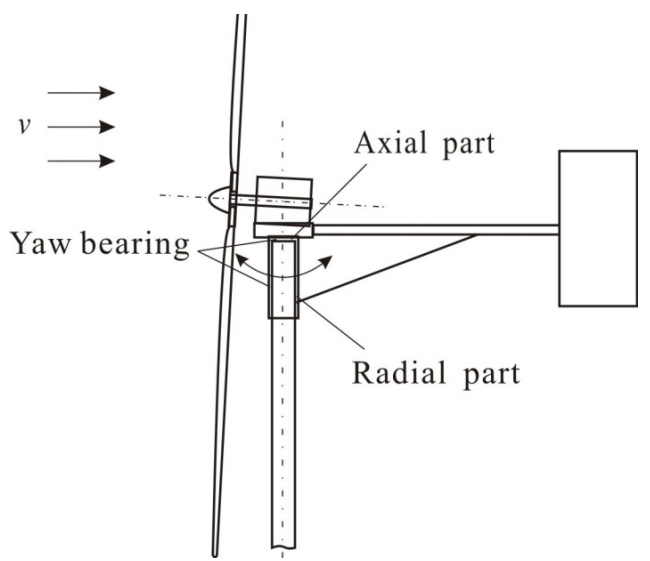

Fig. (2). Location of the yaw wheel bearing of the small-scale island wind turbine generation system.

In the marine tidal current turbine generation device, the yaw system is the key part for the horizontal-axis turbine turning to face the tidal current direction. While there has not been an enough reliable and universal design scheme for the yaw system of tidal current turbine, like that of wind turbine.
Traditional yaw structure of small-scale horizontal-axis wind turbine is not suitable for the tidal current turbine because of the feature of the tidal current direction and the high conductivity of sea water. Although there is sealing transmission slip ting applied in the sea water, the cost is too high. To realize the tidal current turbine yawing to face the current direction freely, we designed a novel yaw structure that does not depend on the transmission slip ting, shown in Fig. (3). The yaw structure consists of the yaw rotation bearing and the tail vane bearing. The yaw rotation bearing mainly sustains the thrust generated by the tidal current flowing through the turbine, the friction during the yaw of the turbine and the pressure produced by the support beam, the blades, the hub, the generator and the tail vane. This bearing should have less friction coefficient and higher compressive strength. In addition, because of the difficulty of maintenance for the device, the bearing should be maintenance-free. It is well known that the dynamic sealing of bearing in the sea water is difficult and costly. In order to achieve the requirement of low maintenance, a good way is to design the bearing that could expose to the sea water and no sealing should be required.

As we know, the generator bearing has important effect on the performance of the generator. Traditional generator that operates in the sea water has the problem of dynamic sealing. In China, the survival time of the sealing generators that many institutes adopted was always very short. We designed a direct-driven generator that could expose to the sea water, not only the stator, but also the rotor. Thus, the generator bearing, shown in Fig. (3), should directly work in the sea water, and must be corrosion resistance.

\subsection{Material Selection of Bearing}

The material, used to fabricate the bearing, should usually have the properties of low friction coefficient, wear resistance, high strength, etc. Especially in the conversion system of marine energy and island wind energy, the material of bearing should also resist corrosion. Traditional metal bearing mainly depend on ball, roller and needle. They 


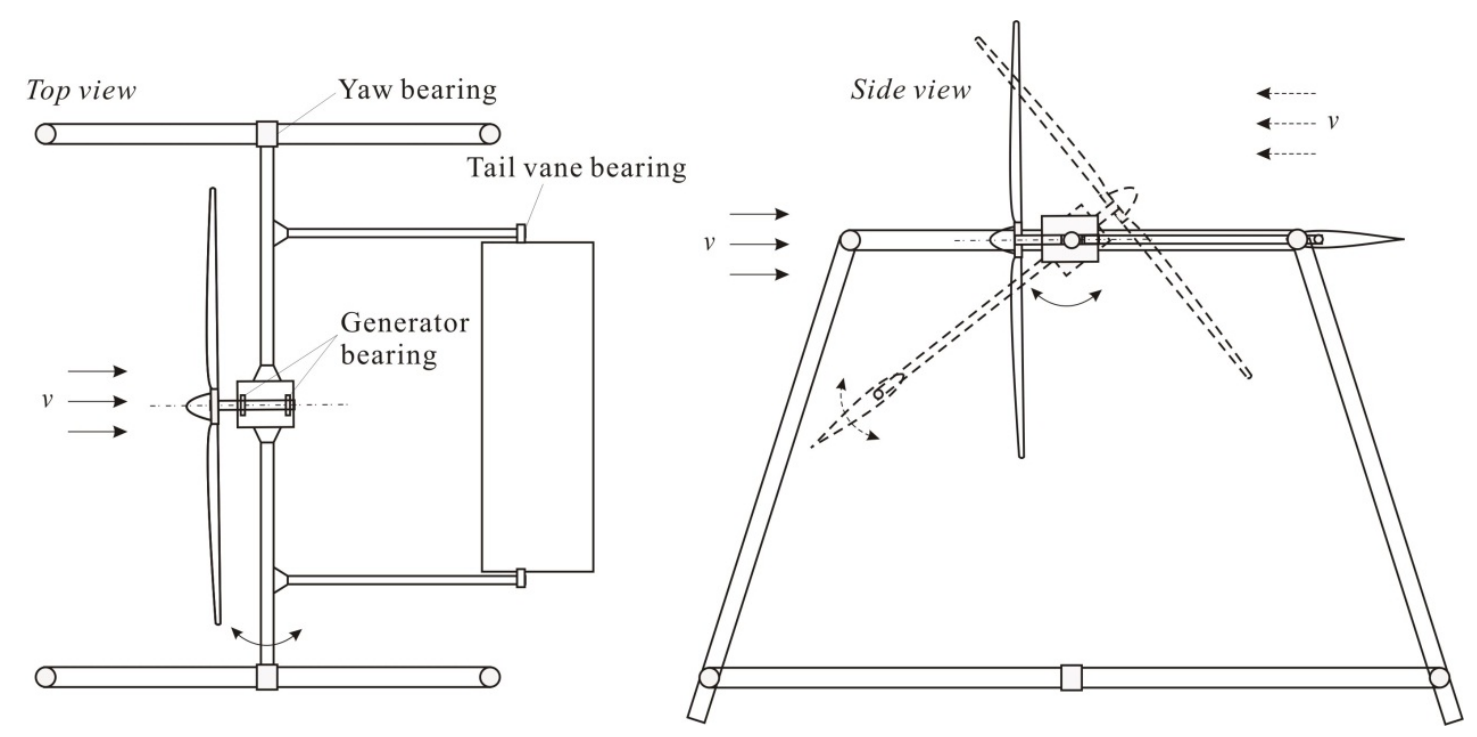

Fig. (3). Location of the yaw rotation bearing and the generator bearing of marine tidal current turbine generation system.

need maintenance and have short service life in marine environment. When used in sea water, the metal bearing also needs to be sealing so as to isolate from the sea water. Because of its excellent comprehensive properties, engineering plastic is a good choose for the manufacture of bearing. Compared with the metal bearing, the plastic bearing has the remarkable feature of maintenance free, especially in marine environment. As one of the five general engineering plastics, POM has many obvious advantages in the application of bearing system. It is widely used in the manufacture of various sliding and rotating machinery, such as gear and bearing.

\section{PROPERTIES ANALYSIS OF POM}

\subsection{Properties of POM}

POM, also known as polyformaldehyde and polyacetal, is a linear unbranched polymer with high density and high crystallinity. It has excellent mechanical properties and chemical resistance [2], and can be used for a very long time from $-40^{\circ} \mathrm{C}$ to $100^{\circ} \mathrm{C}$. Due to high regularity of the molecular chain structure and the chain consisted by carbon and oxygen key that is shorter than carbon-carbon bonds, POM has good stiffness and mechanical strength [9]. As one kind of engineering plastics closest to the metal in the respect of mechanical strength, POM possesses the outstanding advantages of good self-lubrication, fatigue resistance, friction resistance, solvents resistance, small water absorbability, ease of forming and processing, etc. Even in low temperature condition, POM also has good creep resistance, dimensional stability and impact resistance. The wear resistance and self-lubrication of POM are superior to most of the engineering plastics. Meanwhile, POM is endurable against peroxides and oils. Table 1 shows the basic characteristics of general homo-POM.

\subsection{Comparation of Different POM Composites}

General POM has the disadvantages of relatively poor fire resistance, free-burning, low impact strength, high notch sensitivity, poor thermal stability, unsatisfied weather ability, etc. These disadvantages greatly limit the applied range expansion of POM [8]. As with many other synthetic polymers, new POM composites with different qualities would be obtained by adding some ingredients such as glass fibre (GF), carbon fibre (CF), thermoplastic polyurethane (PUR-T), polytetrafluoroethylene (PTFE), etc.

Table 1. The basic characteristics of general POM.

\begin{tabular}{|l|c|}
\hline Density & $1.42 \mathrm{~kg} \mathrm{~cm}^{-3}$ \\
\hline Melting point & $165^{\circ} \mathrm{C}^{\sim} 185^{\circ} \mathrm{C}$ \\
\hline Vicat softening temperature & $160^{\circ} \mathrm{C}$ \\
\hline Thermal deformation temperature & $115^{\circ} \mathrm{C}$ \\
\hline Hardness & $83 \mathrm{~m}$ \\
\hline Crystallinity & $75 \%^{\sim} 85 \%$ \\
\hline Deterioration by heat & $140^{\circ} \mathrm{C}^{\sim} 110^{\circ} \mathrm{C}$ \\
\hline Water absorption & $0.2 \%$ \\
\hline Acids resistance & Weak \\
\hline Friction coefficient & 0.14 \\
\hline Flexure resistance & $73.57 \mathrm{~N} \mathrm{~mm}{ }^{-2}$ \\
\hline Wear resistance & Medium \\
\hline Towing endurance & $53.95 \mathrm{~N} \mathrm{~mm}^{-2}$ \\
\hline Electricity conductivity & $3.7\left(10^{6} \mathrm{~Hz}\right)$ \\
\hline Pressure endurance & $98.10 \mathrm{~N} \mathrm{~mm}{ }^{-2}$ \\
\hline Process ability & Very good \\
\hline Light conductivity & Normal \\
\hline Modulus of elasticity (E) & $3.0 \mathrm{GPa}$ \\
\hline Linear elongation factor & $10\left(10^{-5} \mathrm{~K}^{-1}\right)$ \\
\hline Contraction & $0.0285 \mathrm{~cm} \mathrm{~cm}^{-1}$ \\
\hline Notched impact resistance & $9.0 \mathrm{kJm}{ }^{-2}$ \\
\hline Tensile strength & $61.0 \mathrm{MPa}$ \\
\hline Bending strength & $63.0 \mathrm{MPa}$ \\
\hline
\end{tabular}


Compared with general POM, the blend of POM/GF remarkably improves the performance on strength and stiffness, and its toughness is basically unchanged or slightly reinforced. Meanwhile, it enhances the heat distortion temperature and creep resistance, and reduces the warp. Therefore, the composite based on POM/GF is largely used for mechanical components. The drawback of this composite is that its wear resistance would be reduced slightly. When modified POM by CF, it not only achieves the same reinforced effect like POM/GF composite, but also ensures the wear resistance.

As we know, POM is a high crystalline polymer with high strength and stiffness, and its tensile strength is the highest among all kinds of the engineering plastics. Meanwhile, POM has good impact resistance, and the impact strength of co-POM with medium viscosity could achieve $250 \mathrm{~kJ} \mathrm{~m}^{-2}$. However, due to high crystalline, it is easy to form large spherocrystal structure so that it causes the high notch sensitivity of POM [10]. Thus POM would be destroyed because of being brittle, especially for V-notch. The value of notched impact absorbed energy of POM is only from one fifteenth to one fortieth of that unnotched. By toughening modification, the notched impact strength of POM composites would be enhanced by more than ten times compared with general POM. So far, the most effective toughener of POM is PUR-T. The POM/PUR-T blend could reduce the crystallinity and the spherulite size of general POM, and would dramatically improve the notched impact strength.

For POM components used as friction parts in the condition of relatively high speed and heavy load, owing to lack of sufficient lubrication and difficulty to dissipate the heat generated by the friction, they are easy to deform and wear out faster. Therefore, general POM is usually made into the friction parts used in low speed and light load condition. The wear resistance of POM will be improved through modifying POM with PTFE, silicone oil (Si-oil), graphite, molybdenum disulfide $\left(\mathrm{MoS}_{2}\right)$, liquid lubricant, low molecular polyethylene, etc. After being modified by above materials, the POM composites could be better applied in the productions with high performance requirements of friction and wear, such as gear, bearing, bushing, cam, and so on. POM/PTFE blend has very low friction coefficient and high wear resistance, so it is suitable for the application of high rotation speed and heavy load. When modifying POM by Si-oil, the performance of friction and wear resistance of POM will be improved effectively. In the same condition, the friction coefficient of POM/Si-oil blend is just one half of that of general POM. The PV (the product of load and speed of bearing) limit is more than two times of that of general POM. Therefore, the POM/Si-oil blend is suitable to be fabricated as bearing, gear, pulley, etc. When adding $\mathrm{MoS}_{2}$ into POM, the friction, wear and noise of POM with metal will be reduced. In addition, the blend of POM/PTFE/Si-oil has good molding and friction properties and synergism between PTFE and silicone oil in friction property, and studies indicate that the modified POM blending alloy with 10 mass\% PU and PTFE and Si-oil has the best self-lubrication.

\section{BEARING DESIGN AND TEST}

\subsection{Bearing Design and Manufacture}

In the island wind turbine generation system, the yaw wheel bearing was developed according to the structure of Fig. (2) and the analysis of Section 2.2. Fig. (4) illustrates two kinds of the structure design scheme for the axial bearing. When the wind turbine is used in the island where the wind speed is larger and the wind direction changes quickly and frequently, the damping force is needed to prevent the turbine from turning to face the wind frequently with the change of the wind direction. In another word, the axial bearing used in that condition doesn't need the performance of lowest friction coefficient. The continual swing of the turbine would cause the vibration of the tower, which is very harmful to the safety of the generation system. In this condition, the POM laminated bearing, shown in Fig. (4a), is more suitable as the axial bearing. Meanwhile, it could provide more compressive strength. For the application of the small-scale wind turbine in the island where the wind speed is lower and the wind direction is relatively stable, the lowest possible friction coefficient is needed to reduce the friction loss of the bearing when yawing freely. Therefore, the POM ball bearing shown in Fig. (4b) is a better option in this condition. Compared with the sliding friction of the laminated bearing, the rolling friction of the ball bearing has smaller friction damping.

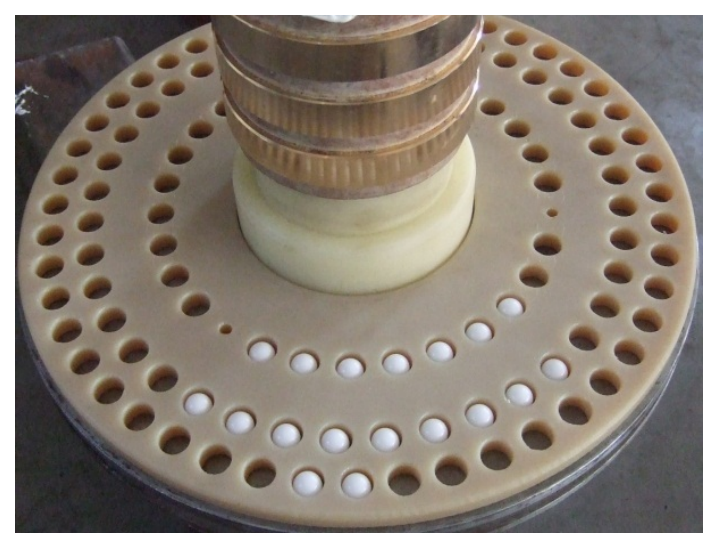

(b)

Fig. (4). Two kinds of axial bearing based on the material of POM: (a) the laminated bearing; (b) the ball bearing. 
Based on the structure of the island wind turbine, the roller bearing, shown in Fig. (5), was designed and manufactured as the radial bearing. This bearing has relatively low requirements in the aspects of the friction and the strength compared with the axial bearing. POM with high wear resistance could be selected as the material of the bearing.

In the marine tidal current turbine generation system, based on the analysis in Section 2.2 and the structure of the generation device shown in Fig. (3), the POM roller bearing was designed as the yaw rotation bearing, illustrated in Fig. (6). The POM roller bearing is exposed to the sea water and is prevented by the entrance of the sediment and biologically by the POM lamination of the bearing terminal. In dry condition, the POM roller has very low friction coefficient. When used in the sea water, the lubrication performance of POM would be improved by the water. Meanwhile, the POM roller has enough compressive strength resistance. Therefore, there is no problem for the POM roller as the key unit of the yaw rotation bearing. And the operation of the device in the field shows that is true.

The generator bearings including the thrust bearing and the bush bearing based on the material of POM were developed according to the analysis in Section 2.2. The thrust bearing, shown in Fig. (7), consists of POM ball, POM plate and other limiting part based on the material of polyamides. It provides the thrust produced by the turbine. The bush bearing, shown in Fig. (8), is composed by the POM bush and the bronze bush, which are fixed on the front end cap and the rotation shaft respectively based on the method of hot shrunk fit. Both of the thrust bearing and the bush bearing are exposed to the sea water, because the generator is not sealed. The sediment and biological couldn't enter into the generator due to the close fit of the bush bearing. Under the condition of water lubrication, the friction damping of these bearings has lower effect on the efficient of the generator.

\subsection{Static Load and Sliding Friction Test}

Although the mechanical strength of the bearing could be estimated according to the characteristic parameters of POM, we made some tests about the compression and impact strength. Fig. (9) shows the static load under different compressive deformation of a ball with a diameter of $30 \mathrm{~mm}$. From the graph, we could see that when the deformation is about $0.56 \mathrm{~mm}$, the compressive stress could achieve $2.5 \mathrm{kN}$. It is well known that POM has the highest fatigue resistance among all kinds of engineering plastics. By the test of the ball, we find that when the compression reaches $2 \mathrm{~mm}$, it could still restore the deformation well. For our $20 \mathrm{~kW}$ tidal current turbine, even if the thrust coefficient equaled to 1.0, the thrust could only reach a maximum of $40 \mathrm{kN}$. In fact, this

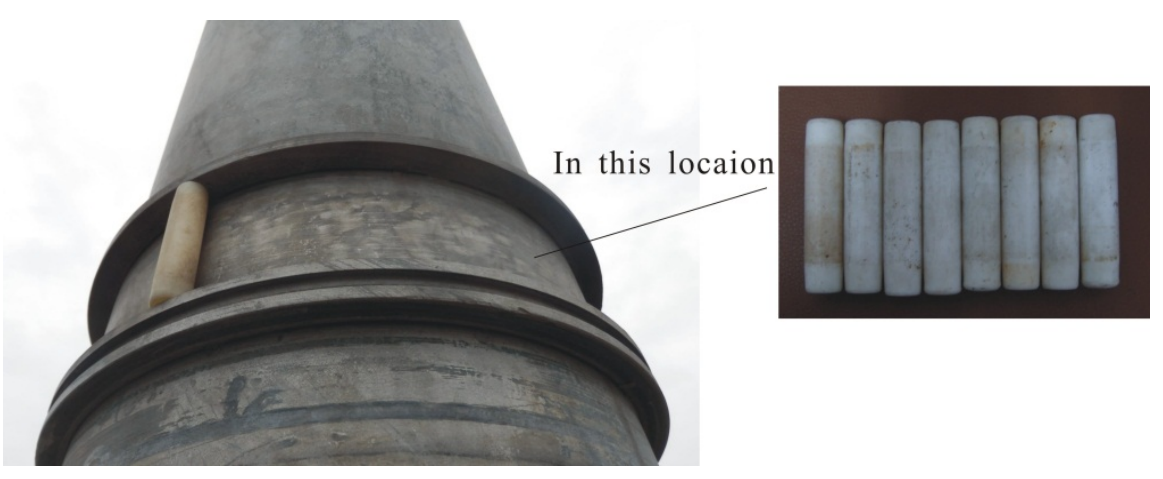

Fig. (5). The POM roller bearing as the radial bearing of island wind turbine.

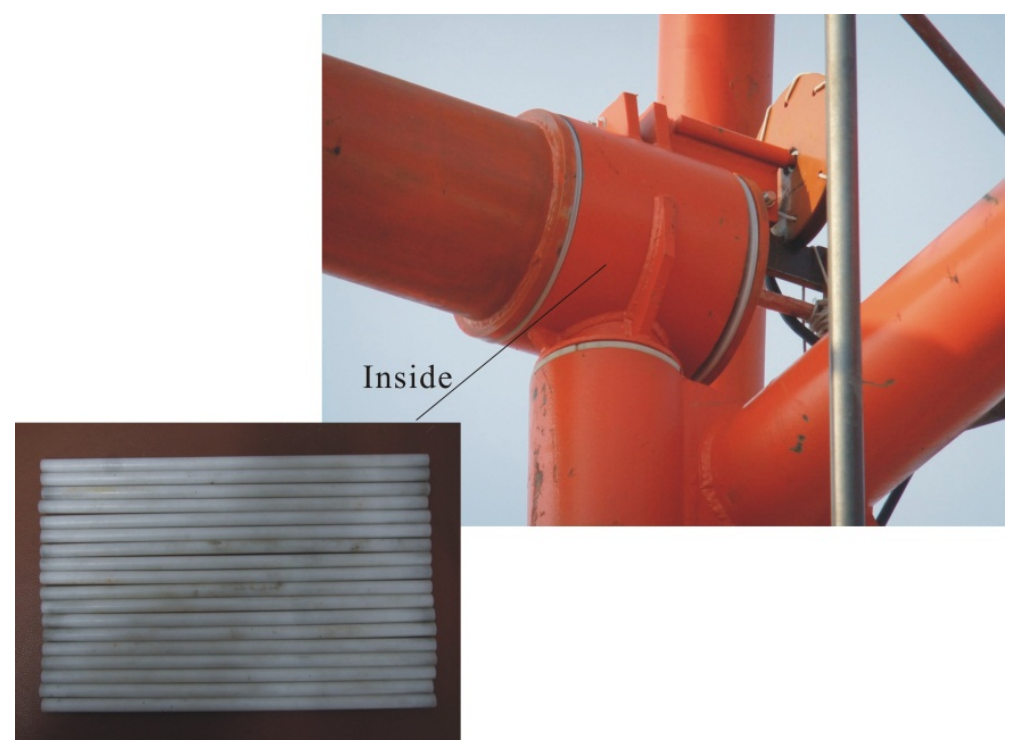

Fig. (6). The yaw rotation bearing of $20 \mathrm{~kW}$ tidal current generation device based on the POM roller. 


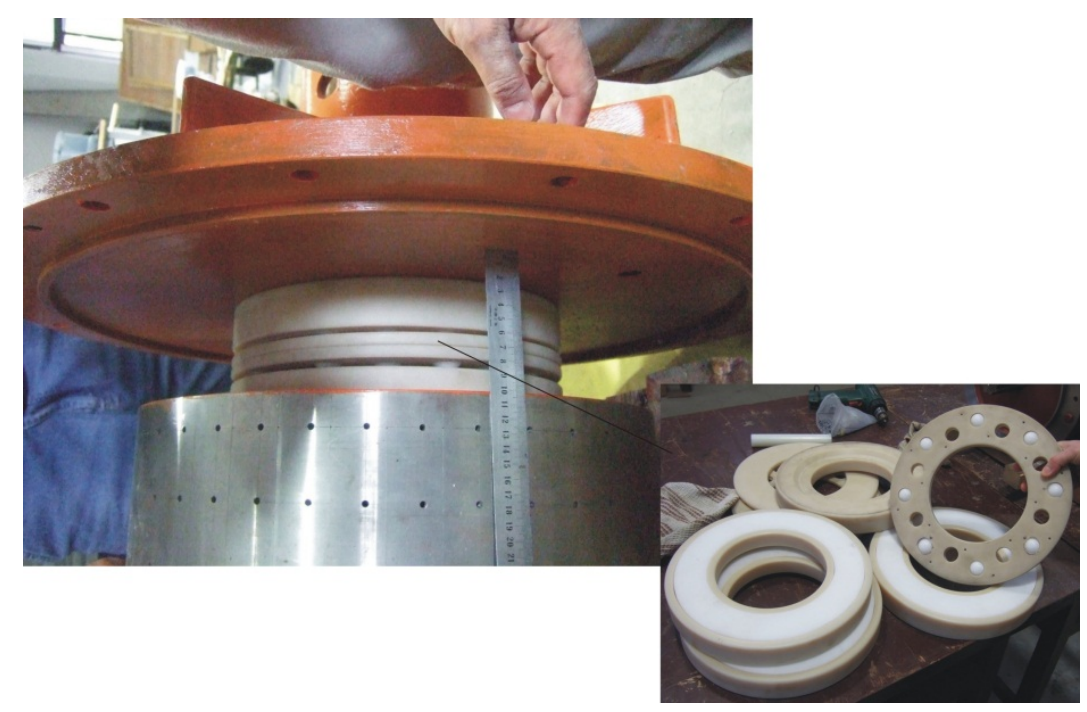

Fig. (7). The thrust bearing in the generator.
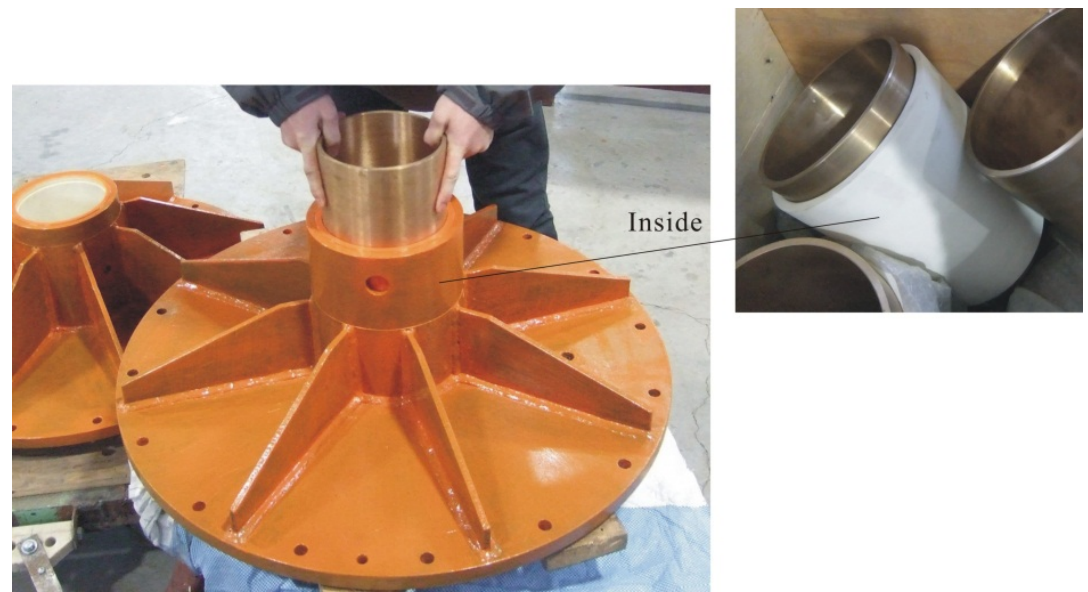

Fig. (8). The bush bearing in the generator.

situation doesn't exist, because in maximum current speed, the thrust coefficient is much less than 1. Meanwhile, for marine tidal current, the duration of the maximum speed is very short. Under the condition of small deformation less than $0.6 \mathrm{~mm}$, sixteen POM balls could provide a support force of $40 \mathrm{kN}$, which would be enough to sustain the thrust produced by the turbine.

For the test of impact strength, a strip POM sample with $100 \mathrm{~mm}$ long, $10 \mathrm{~mm}$ wide and $8 \mathrm{~mm}$ height was provided. According to ISO standard, the notched impact strength achieves $13.4 \mathrm{~kJ} \mathrm{~m}^{-2}$, which shows that POM has high impact strength.

\section{RESULT AND DISCUSSION}

All above bearings were fabricated and applied in the renewable energy generation system that is shown in Fig. (1). The two island wind turbine generation devices were installed in June, 2010. According to the operation, the turbine could yaw to the wind direction very well. Since then, they could generate enough power to supply the island residents. But because of the typhoon and the not enough strong foundation, one of the turbines was blown down in May, 2012. During the repair, we found that the POM bearing had no breakage and several POM rollers of the radial bearing had a little deformation that could not recover. We thought the deformation was caused by the impact during the blowing down of the whole device. However, the deformation had not serious effect on the normal operation of the turbine. After the repair, the two wind turbines still worked until now.

The $20 \mathrm{~kW}$ marine tidal current generation device was put in the offshore in May, 2013. because the marine fouling organisms have a strong impact on the operation of the turbine, hey must be removed from time to time. All of the generator and the yaw rotation device sttill worked well until now.

\section{CONCLUSION}

In this paper, a series of special bearings based on the POM composite were developed and applied in the renewable energy generation system. By analyzing the properties of POM and comparing different POM composites, the composites for the special bearing manufacture were selected. Meanwhile, both the compressive strength and the impact strength of POM were tested and the results indicated that the load resistance could 


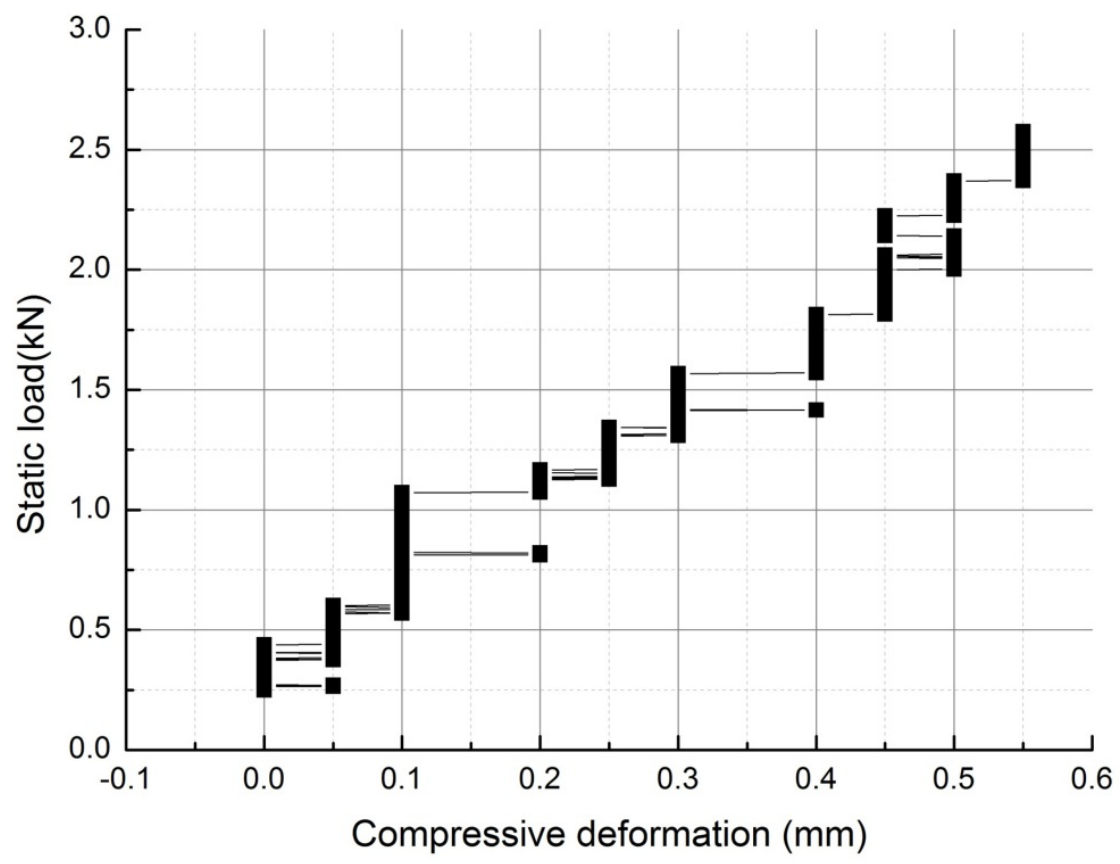

Fig. (9). The static load $v s$ compressive deformation of a POM ball with a diameter of $30 \mathrm{~mm}$.

satisfy the requirement of the generation device. The operation of the generation device adopted the special bearings based on the POM composites shows that it is a good selection for the renewable energy conversion system, especially for the marine renewable energy generation system. Through optimizing the structure, the POM composites or other engineering plastics would be generalized and applied in renewable energy generation device with higher power level.

\section{CONFLICT OF INTEREST}

The authors confirm that this article content has no conflict of interest.

\section{ACKNOWLEDGEMENTS}

This work is sponsored by Science Foundation for Young Teachers of Northeast Normal University (No.14QNJJ009) and Special funds of Marine Renewable Energy of State Oceanic Administration of China (No. GHME2011CL02, No. ZJME2013ZB02).

\section{REFERENCES}

[1] Korpela T, Suvanto M, Pakkanen TT. Wear and friction behavior of polyacetal surfaces with micro-structure controlled surface pressure. Wear 2015; 328-9(0): 262-9.

[2] Feyzullahoglu E, Saffak Z. The tribological behaviour of different engineering plastics under dry friction conditions. Mater Des 2008; 29(1): 205-11.

[3] Pogačnik A, Kalin M. Parameters influencing the running-in and long-term tribological behaviour of polyamide (PA) against polyacetal (POM) and steel. Wear 2012; 290-1(0): 140-8.

[4] Stryczek J, Bednarczyk S, Biernacki K. Strength analysis of the polyoxymethylene cycloidal gears of the gerotor pump. Arch Civil Mech Eng 2014; 14(4): 647-60.

[5] Ünlü B S, Atik E, Köksal S. Tribological properties of polymerbased journal bearings. Mater Des 2009; 30(7): 2618-22.

[6] Benabdallah H, Olender D. Finite element simulation of the wear of polyoxymethylene in pin-on-disc configuration. Wear 2006; 261(11-12): 1213-24.

[7] Dou Q, Feng X, Lu X H. Development and application of polyoxymethylene self-lubrication composite. Polym Mater Sci Eng 2003; 19(01): 36-40.

[8] Cheng YH, Li YY, Liu Y. Development and application of POM product at domestic and overseas. Eng Plast Appl 2009; 37(09): 5964.

[9] Wang XM, Xu ZX, Wang YF, et al. The Production and application of POM. China Plast Ind 2012; 40(03): 46-9.

[10] Xie G, Wang P, Geng K, et al. The study of thermoplastic polyurethane elastomer co-mixing flexibilizing polyoxymethylene. China Rubber/ Plast Technol and Equip 2007; 33(11): 36-9. 